\title{
Suppression or Activation of Immune Responses by Predicted Secreted Proteins of the Soybean Rust Pathogen Phakopsora pachyrhizi
}

\author{
Mingsheng Qi, ${ }^{1}$ James P. Grayczyk, ${ }^{1}$ Janina M. Seitz, ${ }^{2}$ Youngsill Lee, ${ }^{3}$ Tobias I. Link, ${ }^{2}$ Doil Choi, ${ }^{3}$ \\ Kerry F. Pedley, ${ }^{4}$ Ralf T. Voegele, ${ }^{2}$ Thomas J. Baum, ${ }^{1}$ and Steven A. Whitham ${ }^{1,+}$ \\ ${ }^{1}$ Department of Plant Pathology and Microbiology, lowa State University, Ames 50011, U.S.A.; ${ }^{2}$ Institut für Phytomedizin, \\ Universität Hohenheim, Otto-Sander-Straße 5, 70599 Stuttgart, Germany; ${ }^{3}$ Department of Plant Science, Plant Genomics and \\ Breeding Institute, Seoul National University, Seoul 151-921, Korea; and ${ }^{4}$ Foreign Disease-Weed Science Research Unit, \\ United States Department of Agriculture-Agricultural Research Service, Ft. Detrick, MD 21702, U.S.A.
}

Accepted 20 September 2017.

\begin{abstract}
Rust fungi, such as the soybean rust pathogen Phakopsora pachyrhizi, are major threats to crop production. They form specialized haustoria that are hyphal structures intimately associated with hostplant cell membranes. These haustoria have roles in acquiring nutrients and secreting effector proteins that manipulate host immune systems. Functional characterization of effector proteins of rust fungi is important for understanding mechanisms that underlie their virulence and pathogenicity. Hundreds of candidate effector proteins have been predicted for rust pathogens, but it is not clear how to prioritize these effector candidates for further characterization. There is a need for high-throughput approaches for screening effector candidates to obtain experimental evidence for effector-like functions, such as the manipulation of host immune systems. We have focused on identifying effector candidates with immune-related functions in the soybean rust fungus $P$. pachyrhizi. To facilitate the screening of many $P$. pachyrhizi effector candidates (named PpECs), we used heterologous expression systems, including the bacterial type III secretion system, Agrobacterium infiltration, a plant virus, and a yeast strain, to establish an experimental pipeline for identifying PpECs with immune-related functions and establishing their subcellular localizations. Several PpECs were identified that could suppress or activate immune responses in nonhost Nicotiana benthamiana, N. tabacum, Arabidopsis, tomato, or pepper plants.
\end{abstract}

Plant pathogens deploy effector proteins to manipulate hostplant cell functions in order to establish and maintain their infections (Dodds and Rathjen 2010). Unraveling the functions of effectors in plants is necessary for understanding the mechanisms that control virulence and pathogenicity and is expected to aid in the development of plant disease resistance (Dangl et al. 2013). Many successful transcriptome and genome

Mention of trade names or commercial products in this publication is solely for providing specific information and does not imply recommendation or endorsement by the U.S. Department of Agriculture (USDA). USDA is an equal opportunity provider and employer. The complete nondiscrimination policy can be found on the USDA website.

${ }^{\dagger}$ Corresponding author: Steven A. Whitham; E-mail: swhitham@iastate.edu

*The $\boldsymbol{e}$-Xtra logo stands for "electronic extra" and indicates that two supplementary figures and two supplementary tables are published online.

@ 2018 The American Phytopathological Society sequencing projects have led to the discovery of thousands of predicted secreted effector candidates in filamentous plant pathogens (Cantu et al. 2013; Kamoun 2007; Nemri et al. 2014; Petre et al. 2015; Saunders et al. 2012; Schmidt and Panstruga 2011). These successes present the new challenge of identifying effector proteins and establishing their functions that determine the outcomes of interactions between crop plants and their pathogens.

One major function of effectors is suppression of host immunity to promote virulence (Dou and Zhou 2012; Jones and Dangl 2006). This is necessary because plant defenses are activated upon recognition of conserved molecules or specific effector proteins produced by pathogens (Chisholm et al. 2006; Jones and Dangl 2006; Thomma et al. 2011). Pathogen-associated molecular patterns (PAMPs) are conserved molecules that are detected by pattern recognition receptors on the plant cell surface and trigger the basal defense response known as PAMP-triggered immunity (PTI) (Ade et al. 2007; Zipfel et al. 2004, 2006). Some responses associated with PTI are callose deposition, reactive oxygen species (ROS) burst, and increased expression of defense genes (Schwessinger and Zipfel 2008). Successful pathogens overcome PTI by interfering with immune responses through the action of secreted effector proteins (Jones and Dangl 2006). In response to effector proteins, host plants have evolved a second, more specific defense response known as effector-triggered immunity (ETI), which is frequently associated with hypersensitive cell-death responses (HR) (Dangl et al. 2013). HR is elicited upon recognition of effector proteins or their actions by corresponding resistance proteins of the nucleotide binding site leucinerich repeat class, and it is particularly effective against biotrophic pathogens (Gill et al. 2015; Glazebrook 2005).

Phakopsora pachyrhizi is an obligate biotrophic fungal pathogen that causes soybean rust. Based on transcriptomic studies, the $P$. pachyrhizi in planta secretome is currently estimated to comprise at least 851 proteins (de Carvalho et al. 2017), a size that falls within the range of secretomes predicted for other rust fungi (Petre et al. 2014). Like other rusts, it is currently not possible to use bioinformatics to predict which of these 851 proteins might be effectors. During infection, rust fungi produce specialized hyphal structures, so-called haustoria, within the cell walls but outside of the cytoplasm of their host plants. The haustoria of rust pathogens interact intimately with host cells and they are thought to be a site enriched for the production and secretion of effectors (Catanzariti et al. 2007). Two studies have focused on sequencing the haustorial transcriptome of $P$. pachyrhizi, with the goal of identifying haustoria-expressed secreted proteins. 
Link et al. (2014) identified 156 unique mRNA transcripts encoding proteins with predicted signal peptides that were greater than 50 aa in length (named $P$. pachyrhizi effector candidates [PpECs]), and Kunjeti et al. (2016) identified 35 haustoria-expressed candidate secreted effector proteins (CSEPs) ranging in size from 55 to 357 aa. Of the 35 CSEPs identified by Kunjeti et al. (2016), 31 were present in the Link et al. (2014) transcriptome, but, of these, only 15 were annotated as secreted, suggesting that many sequences were most likely not full-length. de Carvalho et al. (2017) found that 101 of their 851 in planta-expressed secreted proteins overlapped with the 156 PpECs identified by Link et al. (2014). A reference genome combined with these transcriptomic data sets would provide a more comprehensive prediction of the $P$. pachyrhizi secretome, but the complexity of the $P$. pachyrhizi genome has prohibited sequencing and assembly of a high-quality genome (Loehrer et al. 2014). Nevertheless, the proteins predicted to bear signal peptides and shown to be present in haustoria provide a large number of potential effectors.

The obligate biotrophic lifestyles of rust fungi constrain molecular and genetic studies that are needed to identify effectors and determine their functions in immune suppression or activation. An approach to overcome this limitation is to use surrogate effector delivery systems and nonhost plants that facilitate rapid and reproducible screens for effector-like functions. The bacterial type III secretion system (T3SS) has become a widely used tool for delivering candidate effector proteins into host cells (Fabro et al. 2011; Sohn et al. 2007). A T3SS signal peptide is fused to the amino terminus of the candidate effectors minus their own signal peptides, enabling their secretion out of bacteria into plant cells. Agrobacterium infiltration requires cloning the candidate effectors plus or minus signal peptide into a T-DNA expression vector, and viral expression requires cloning the candidate effectors into a viral genome and infecting the experimental plants.

Recently, several studies with the goal of characterizing candidate effectors from a variety of rust pathogens have taken advantage of surrogate expression systems coupled with $N$. benthamiana as a substitute for the natural hosts (Cheng et al. 2017; Dagvadorj et al. 2017; de Carvalho et al. 2017; Kunjeti et al. 2016; Liu et al. 2016; Petre et al. 2015, 2016a and b; Qi et al. 2016; Ramachandran et al. 2017). In each of these studies, a handful of candidate effectors of the pathogens causing wheat rusts (stem, leaf, and stripe), poplar rust, or soybean rust were screened for immune suppression functions. With respect to $P$. pachyrhizi, Kunjeti et al. (2016) agroinfiltrated constructs expressing four CSEPs into $N$. benthamiana leaves and found that two promoted the virulence of Phytophthora infestans and de Carvalho et al. (2017) identified six predicted secreted proteins that suppressed bacterial-induced HR in N. benthamiana. Green fluorescent protein (GFP) tags fused to the candidate effector proteins have been used to determine their subcellular localization when expressed within $N$. benthamiana cells (de Carvalho et al. 2017; Petre et al. 2015, 2016a and b; Qi et al. 2016; Sperschneider et al. 2017), and epitope tags have also been used to facilitate pull-down assays that were combined with mass spectrometry to identify interacting plant proteins (Petre et al. 2015, 2016b). Arabidopsis thaliana has also proved useful as a surrogate plant for expression of GFP fusions and identification of immune suppression functions (Germain et al. 2016).

Our primary goal was to use approaches that enabled us to screen a large number of PpECs to determine if any of them possess effector-like functions related to suppressing or activating plant immune responses. We cloned the coding sequences of 82 of 156 PpECs (Link et al. 2014) into a variety of vectors that enable delivery into plants through the T3SS, Agrobacterium infiltration, or virus-based expression. These expression systems enabled the application of a variety of assays designed to identify effectors that suppress or activate PTI or ETI in N. benthamiana, N. tabacum, A. thaliana, tomato, or pepper. Expression in yeast enabled the identification of PpECs that could suppress BAX-induced cell death. The potential localization of PpECs in planta was investigated by transiently expressing GFP fusions in $N$. benthamiana. We describe a large-scale effector biology pipeline that led to the identification of 17 PpECs that suppress plant immunity, and we present data that lay the foundation for future studies to investigate mechanisms underlying $P$. pachyrhizi virulence and pathogenicity.

\section{RESULTS}

Cloning PpECs from the LA04-1 isolate of $P$. pachyrhizi.

Link et al. (2014) identified 156 PpECs, based on haustorial expression, presence of a signal peptide, and lack of protein domains, expected to retain the predicted proteins within the fungal cell. We were interested in further characterizing this set of PpECs for potential functions associated with immune responses and to determine their localizations within plant cells. The first step was to use 96 primer pairs, designed from the sequences of the Link et al. (2014) contigs, to amplify the coding regions minus the predicted signal peptides of the 96 longest open reading frames (ORFs) (Supplementary Fig. S1; Supplementary Tables S1 and S2). For simplicity, the polymerase chain reaction (PCR) products and corresponding clones were assigned arbitrary names based on size, beginning with PpEC1 as the largest and ending with PpEC96 as the smallest. The template used for PCR reactions was cDNA synthesized from RNA extracted from soybean leaves at 14 days postinfection (dpi) with P. pachyrhizi (isolate LA04-1). From these reactions, 82 ORFs minus the signal peptides were successfully cloned into the pCR8 Gateway entry vector. The 82 clones were re-sequenced to confirm their authenticity and to determine if the sequences of isolate LA04-1 deviated from the sequences of isolate Thail of Link et al. (2014). The cloned PpEC amino acid sequences are identical or differ by just one or two residues, with the exception of PpEC69, which differs by five residues between the two isolates. Subsequently, Gateway cloning was used to move the 82 PpEC ORFs into bacterial, T-DNA, viral, and yeast expression vectors for use in the immune suppression and activation assays or localization studies described below (Fig. 1).

\section{PpECs that suppress HR and basal defense identified via T3S from bacteria.}

To express PpEC ORFs minus their signal peptides from bacteria, their sequences were mobilized into the bacterial T3SS vector pEDV6 (effector detector vector 6), which previously has been used to deliver nonbacterial proteins into plants (Fabro et al. 2011; Sohn et al. 2007; Upadhyaya et al. 2014). These constructions created a fusion of the AvrRPS4 T3SS signal peptide to the amino terminus of each PpEC (Fig. 1A). These 82 plasmids plus the empty pEDV6 were introduced into Pseudomonas syringae pv. tomato DC3000, CUCPB5115 (Pseudomonas syringae pv. tomato DC3000 $\triangle$ CEL, a nonvirulent DC3000 mutant lacking key effector proteins), and Pseudomonas fluorescens EtHAn (a nonpathogen engineered to carry the T3SS) (Fig. 1A) (Thomas et al. 2009). The resulting strains were blunt syringe-inoculated into leaves of Glycine max cv. Williams 82, the host of P. pachyrhizi, and the nonhost plants Nicotiana tabacum cv. Xanthi, N. benthamiana, or A. thaliana ecotype Col-0.

To test for suppression of HR, Pseudomonas syringae pv. tomato DC3000 strains carrying the 82 PpECs were inoculated into leaves of $N$. tabacum, $N$. benthamiana, and soybean to screen for HR suppressor activities. Pseudomonas syringae pv. tomato DC3000 carries the effectors HopQ1-1 and AvrD, which elicit HR in Nicotiana spp. and soybean, respectively (Kobayashi et al. 1989; Wei et al. 2007). As reported recently, PpEC23 was 
able to suppress the HR caused by Pseudomonas syringae pv. tomato DC3000 on all plants (Qi et al. 2016). All other strains maintained the ability to cause robust HR in planta similar to the empty vector control, indicating that the 81 remaining PpECs cannot suppress HR elicited by HopQ1-1 or AvrD (Table 1).
Two assays were employed to screen for suppressors of basal defense. First, it was previously shown that inoculation of nonpathogenic Pseudomonas fluorescens EtHAn induces basal defenses in $N$. benthamiana leaves that suppress the ability of Pseudomonas syringae pv. tomato DC3000 to induce macroscopic HR when

Table 1. Properties of 17 Phakopsora pachyrhizi effector candidates (PpECs) showing evidence for immune suppression-related phenotypes

\begin{tabular}{|c|c|c|c|c|c|c|c|c|c|c|}
\hline \multirow{3}{*}{$\begin{array}{l}\text { PpEC } \\
\text { no. }\end{array}$} & \multirow[b]{3}{*}{ Annotation } & \multirow[b]{3}{*}{ Lineage specificity ${ }^{a}$} & \multirow[b]{3}{*}{ Localization $^{\mathbf{b}}$} & \multirow{3}{*}{$\begin{array}{c}\Delta \text { Basal } \\
\text { defense }^{c}\end{array}$} & \multirow{3}{*}{$\begin{array}{c}\Delta \text { Callose } \\
\text { deposition }\end{array}$} & \multirow[b]{3}{*}{$\Delta \mathbf{H R}^{\mathrm{c}}$} & \multirow{3}{*}{$\begin{array}{l}\text { Yeast cell-death } \\
\text { suppression }\end{array}$} & \multirow{2}{*}{\multicolumn{3}{|c|}{$\begin{array}{r}\text { HR induction }^{\mathrm{d}} \\
\text { Pepper } \\
\end{array}$}} \\
\hline & & & & & & & & & & \\
\hline & & & & & & & & Tomato & $\mathbf{C M}$ & ECW \\
\hline $\mathrm{PpEC} 3$ & $\begin{array}{l}\text { Fumarate reductase } \\
\text { flavoprotein subunit }\end{array}$ & No & $\mathrm{C}$ & + & + & No & Negative & - & - & - \\
\hline РpEC6 & Protein disulfide isomerase & No & $\mathrm{C}$ & +++ & + & No & Medium & + & - & - \\
\hline PpEC7 & Unknown & No & $\mathrm{C}$ & + & ++ & No & Negative & - & - & - \\
\hline PpEC9 & Unknown & Pucciniales & $\mathrm{C}+\mathrm{N}$ & ++ & ++ & No & Negative & - & + & + \\
\hline PpEC10 & Unknown & No & Nucleolus & $+1-$ & - & No & Negative & - & + & - \\
\hline PpEC14 & Glycoside hydrolase & No & $\mathrm{N}$ & ++ & ++ & No & Medium & - & - & - \\
\hline PpEC15 & Aspartic proteinase & No & $\mathrm{N}$ & ++ & +++ & No & Medium & - & - & - \\
\hline PpEC16 & Unknown & P. pachyrhizi /orphan & $\mathrm{C}$ & $+1-$ & ++ & No & Negative & - & + & + \\
\hline PpEC17 & Unknown & No & $\mathrm{C}+\mathrm{N}$ & ++ & + & No & Negative & - & - & - \\
\hline PpEC23 & Unknown & Pucciniales & $\mathrm{C}^{*}$ & +++ & +++ & Yes & Negative & - & - & - \\
\hline PpEC35 & $\begin{array}{l}\text { Anthranilate } \\
\text { phosphoribosyltransferase }\end{array}$ & No & $\mathrm{C}$ & ++ & + & No & Weak & - & - & - \\
\hline PpEC36 & Rust transferred protein & Pucciniales & $\mathrm{C}+\mathrm{N}$ & + & - & No & Negative & - & - & - \\
\hline PpEC49 & Unknown & Pucciniales & $\mathrm{C}$ & +++ & +++ & No & Strong & - & - & - \\
\hline PpEC77 & Unknown & No & $\mathrm{C}+\mathrm{N}^{*}$ & ++ & ++ & No & Weak & - & - & - \\
\hline PpEC81 & Unknown & P. pachyrhizi & $\mathrm{C}+\mathrm{N}^{*}$ & + & ++ & No & Weak & - & - & - \\
\hline PpEC82 & Unknown & Pucciniales & $\mathrm{C}+\mathrm{N}^{*}$ & +++ & +++ & No & Strong & - & - & - \\
\hline PpEC86 & Unknown & No & $\mathrm{C}+\mathrm{N}$ & +++ & +++ & No & Medium & - & - & - \\
\hline
\end{tabular}

${ }^{\text {a }}$ No means no apparent lineage specificity; Pucciniales, lineage specificity to the rust fungi; P. pachyrhizi, specific to Phakopsora pachyrhizi; and orphan, no clustering possible with the protein.

${ }^{\mathrm{b}}$ Subcellular localization: $\mathrm{C}$, cytoplasmic; $\mathrm{N}$, nuclear; and *, strong protein aggregation.

${ }^{\mathrm{c}} \Delta$ indicates suppression; HR, hypersensitive response.

${ }^{\mathrm{d}} \mathrm{CM}$, pepper cultivar CM334; and ECW, pepper cultivar ECW-30R.

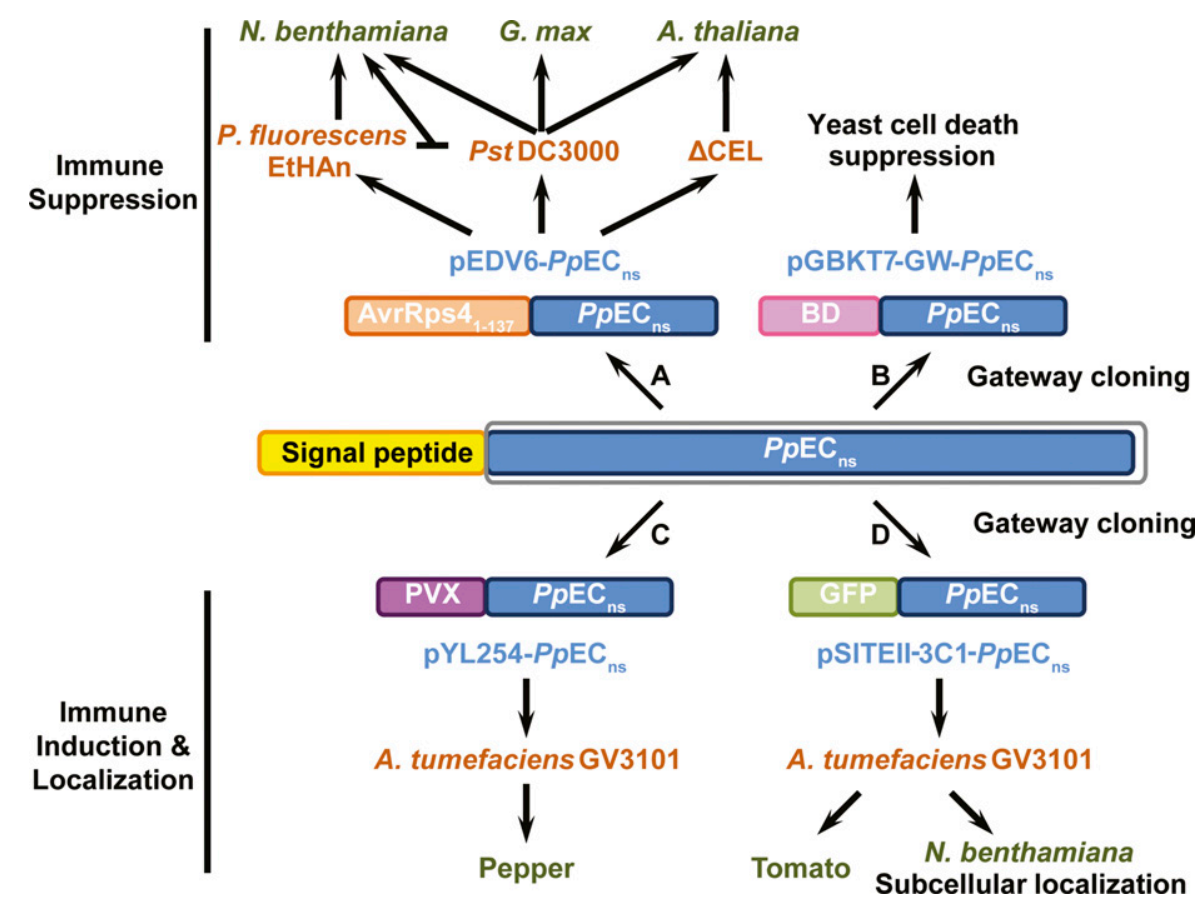

Fig. 1. Experimental pipeline for identifying Phakopsora pachyrhizi effector candidates (PpECs) with immune related functions and establishing their subcellular localizations. The open reading frame (ORF) of PpECs without their signal peptides is represented by $\mathrm{PpEC}_{\mathrm{ns}}$, the Pseudomonas fluorescens effector to host analysis by P. fluorescens EtHAn, Pseudomonas syringae pv. tomato DC3000 by Pst DC3000, Pseudomonas syringae pv. tomato DC3000 carrying a deletion of the conserved effector locus by $\triangle$ CEL. pGBKT7-GW is a Gateway-compatible yeast expression vector that creates a fusion of the Gal4 DNA-binding domain to the amino terminus of $\mathrm{PpEC}_{\mathrm{ns}}, \mathrm{pYL} 254$ is the infectious clone of Potato virus $X$ in a T-DNA vector $\left(\mathrm{PpEC}_{\mathrm{ns}}\right.$ were cloned into the viral genome at a duplicated coat protein site), pSITEII-3C1 is a Gateway-compatible T-DNA vector in which the green fluorescent protein is fused to the amino terminus of the $\mathrm{PpEC}_{\mathrm{ns}}$. The primary purpose for the materials generated for this work are indicated to the left, but they may also be used for other kinds of assays. 
subsequently inoculated into the same area $7 \mathrm{~h}$ later $(\mathrm{Oh}$ and Collmer 2005) (Fig. 2A). In a control experiment, we confirmed that EtHAn carrying empty pEDV6 suppresses HR induced by Pseudomonas syringae pv. tomato DC3000 as expected (Fig. 2B). EtHAn strains carrying each PpEC were then inoculated in $N$. benthamiana leaves, and, $7 \mathrm{~h}$ later, overlapping sites were inoculated with Pseudomonas syringae pv. tomato DC3000. Of the 82 PpECs, 17 enabled DC3000-induced HR to a varying extent (Table 1). The HR observed in the overlapping areas was placed into three categories: + , scattered cell death; ++, cell death occupied approximately half the overlapping area; and +++ , cell death occupied most of the overlapping area (Fig. $2 \mathrm{C}$ to E). Among the 17 positive PpECs, five (PpEC6, PpEC23, PpEC49, PpEC82, and PpEC86) were placed in the +++ category, which we interpret as the strongest suppressors in this assay.
In the second basal defense suppression assay, we screened each PpEC for suppression of callose deposition. The Pseudomonas syringae pv. tomato DC3000 $\triangle$ CEL strain lacks some key effectors and, as a result, induces extensive callose deposition in A. thaliana Col-0 leaves (Fig. 2F), which contrasts with wild-type Pseudomonas syringae pv. tomato DC3000, which induces relatively little callose deposition (Fig. 2F) (DebRoy et al. 2004). Leaves of Col-0 plants were inoculated with Pseudomonas syringae pv. tomato DC3000 $\triangle$ CEL expressing individual PpECs and, at 1 day after inoculation, leaves were stained for callose. Fifteen of the PpEC clones significantly suppressed callose deposition to varying extents (Table 1). Interestingly, the PpEC clones identified in these two assays were consistent, with just two exceptions, PpEC10 and PpEC36, which were relatively weak suppressors of basal defenses and did not suppress callose deposition. These data suggest
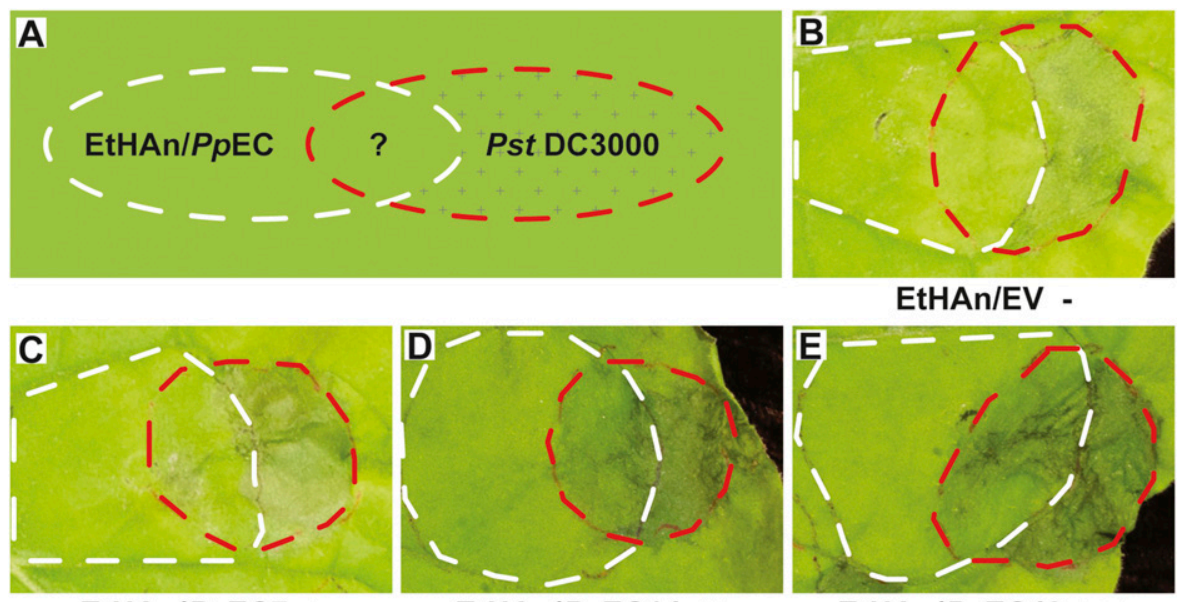

EtHAn/PpEC14 ++
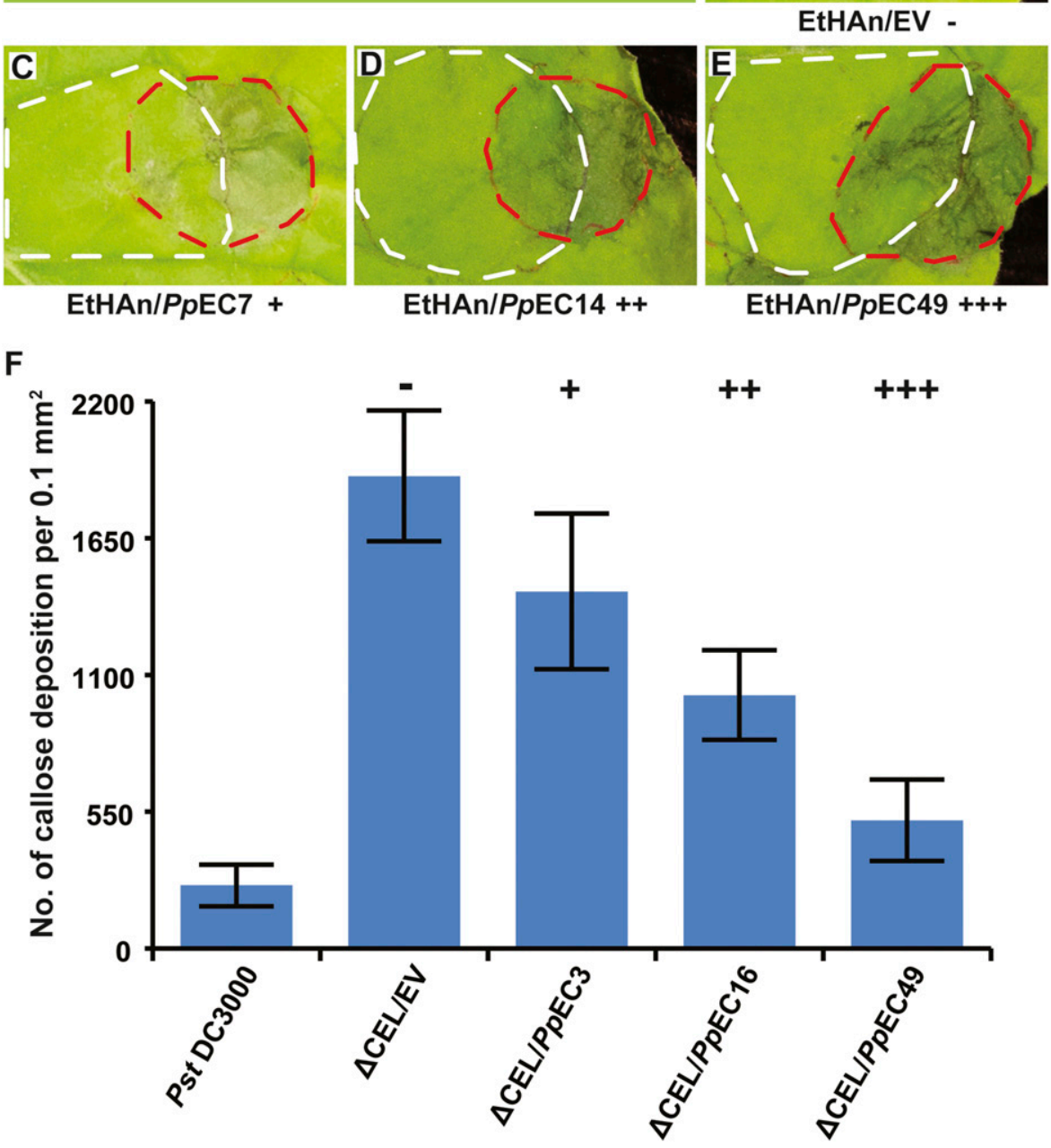

Fig. 2. Examples of results from basal defense suppression assays. A to E, Suppression of basal defense caused by Pseudomonas fluorescens EtHAn expressing Phakopsora pachyrhizi effector candidates (PpECs). A, Diagram of the assay. The question mark (?) indicates the region of overlap that was monitored for response to bacterial infiltrations. B to E, Different levels of hypersensitive cell-death responses were consistently observed in the overlapping areas of EtHAn strains and Pseudomonas syringae pv. tomato DC3000, representing the different phenotypes of basal defense suppression. This assay was repeated three times. F, Suppression of callose deposition induced by inoculation of Pseudomonas syringae pv. tomato DC3000 $\Delta$ CEL expressing PpECs in Arabidopsis leaves. Callose deposition in 36 leaf regions was analyzed and averaged. The error bars indicate the standard deviations of the numbers of callose deposits. Wild-type Pseudomonas syringae pv. tomato DC3000 is shown as a positive control for suppression of callose deposition. A - symbol means negative; +, weak; +, medium; and +++, strong. 
that $P$. pachyrhizi delivers a set of effectors into plants to suppress induced basal defenses associated with PTI.

\section{Suppression of BAX-induced cell death in yeast.}

The $82 \mathrm{PpEC}$ sequences minus signal peptide were cloned into pGBKT7-GW and the resulting plasmids (pGBKT7-GW-PpEC) were introduced into yeast strain BF264-15Dau to test if any of them suppressed yeast cell death caused by BAX (Fig. 1B). BF264-15Dau carries the plasmid YEp51-bax, which expresses the BAX protein in the presence of galactose (Zha et al. 1996). BAX causes cell death in yeast with pleiotropic effects, including ROS production, cytochrome c release, and DNA fragmentation (Abramovitch et al. 2003). Surprisingly, 54 of 82 PpECs were able to suppress yeast cell death to various extents, and, based on growth of the yeast strains, they were placed into four groups (strong, medium, weak, and negative) (Table 1). The 14 PpECs classified as strong suppressors of BAX-induced cell death grew at a rate comparable to the positive control (Fig. 3A). Of the remaining PpECs, 28 and 12 were classified as moderate and weak suppressors of BAX-induced cell death, respectively, and 28 displayed no growth at all, demonstrating that they had no ability to suppress cell death in this assay. We divided the $82 \mathrm{PpEC}$ sequences into two groups containing the 41 largest predicted proteins ( 207 to $670 \mathrm{aa}$ ) and the 41 smallest predicted proteins ( 89 to 206 aa). Interestingly, the ability to suppress BAX-induced cell death is not distributed evenly among these groups $(P<0.0001$, Fisher's exact test) (Fig. 3B). The group of small PpEC clones contains over twice as many proteins that suppress yeast cell death in this assay, with disproportionate numbers in the strong and medium categories. These data suggest that the smaller PpEC proteins
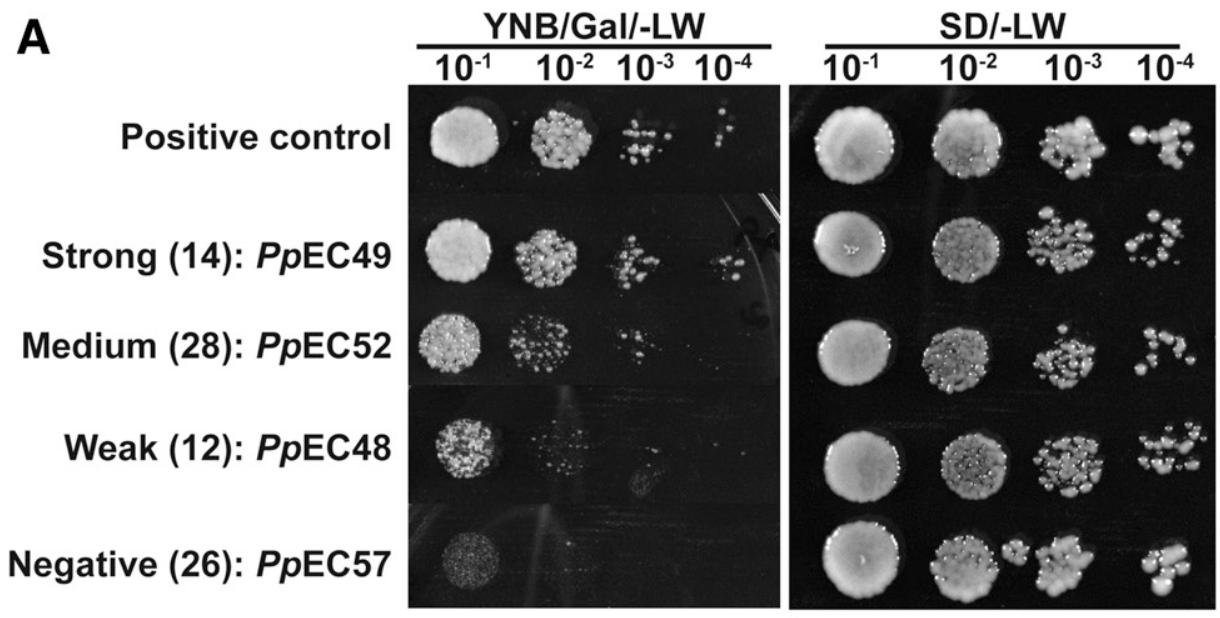

B

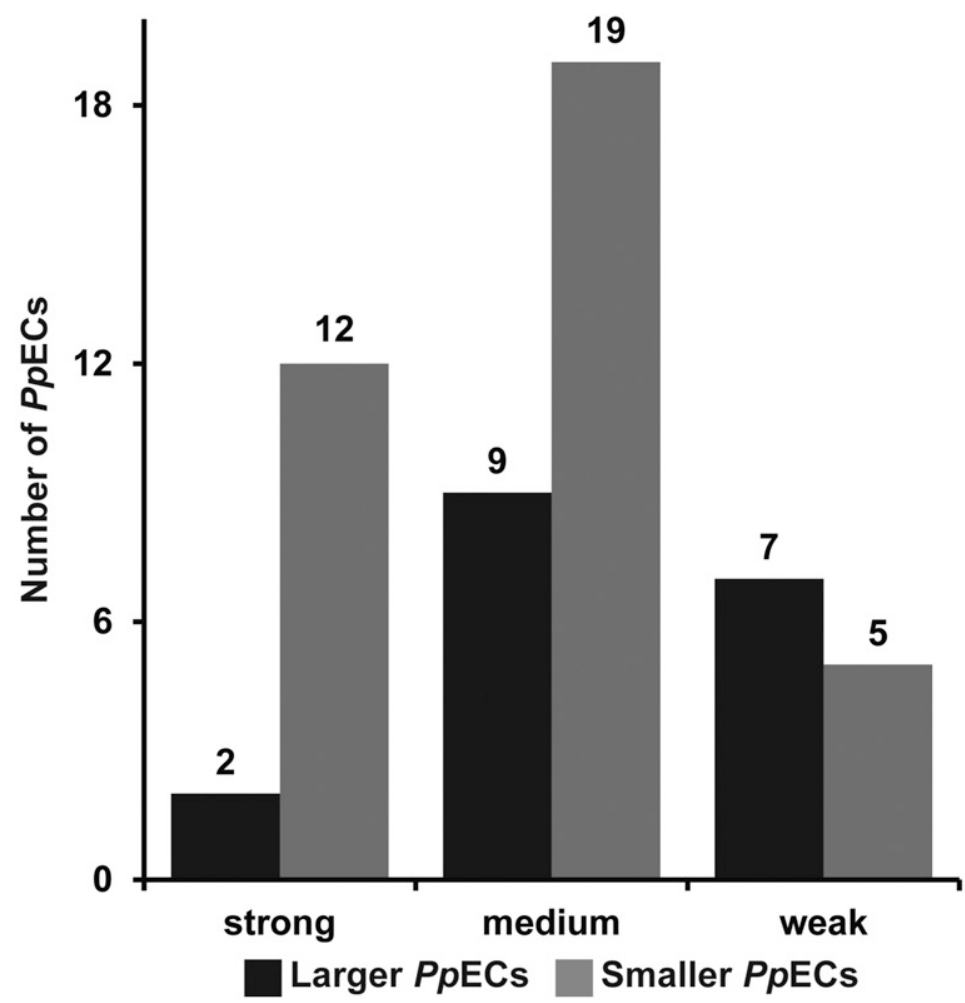

Fig. 3. Examples of results from the yeast BAX-induced cell-death suppression assays. A, Growth phenotypes of serial dilutions of yeast strains grown on cell death induction medium. Phakopsora pachyrhizi effector candidates (PpECs) with representative phenotypes were chosen for display. Strong suppressors were defined by growth detected at the $10^{-4}$ dilution, medium suppressors were defined by growth detected to the $10^{-3}$ dilution, weak suppressors grew at the $10^{-1}$ or $10^{-2}$ dilution, and negatives did not grow at any dilution. The number of PpECs assigned to each phenotypic class are shown in parentheses. This assay was repeated two times. B, Distribution of the different positive phenotypes among the 41 larger and 41 smaller PpECs. 
may be more likely to have roles in interfering with broadly conserved cell-death processes.

\section{Subcellular localization of PpECs in N. benthamiana.}

To determine where PpEC proteins localize when they are expressed inside plant cells, we cloned the $82 \mathrm{PpEC}$ sequences minus their signal peptides into pSITEII-3C1 (Martin et al. 2009), to fuse the GFP reporter to their amino termini (Fig. 1D). These plasmids were transformed into Agrobacterium tumefaciens so that the GFP fusion proteins could be transiently expressed in $N$. benthamiana leaves following agroinfiltration. To determine the subcellular localization of the 82 GFP-PpEC fusions, we visualized GFP fluorescence by epifluorescence microscopy in $N$. benthamiana epidermal cells. We coexpressed the unfused mCherry protein to provide a control for protein expression and background fluorescence in the cells, due to its distribution in both nuclei and cytoplasm. There were four basic patterns of GFP distribution in the cells, cytoplasmic, nuclear, nucleolar, and cytoplasmic + nuclear (Table 1). We selected five of the GFP-PpEC fusion proteins representative of the distribution patterns for confocal microscopy, to gain a more detailed view of the localization (Fig. 4). Of the 82 GFP-PpEC fusion proteins tested, 33 appeared to be evenly distributed in both the nucleus and the cytoplasm (Fig. $4 \mathrm{~A}$ to D). Another 16 GFP-PpECs also were observed in both cytoplasm and nuclei, but, in the cytoplasm, the fusion proteins appear to be located mainly in small bodies, which could be organelles, other subcellular compartments, or artifacts of protein aggregation (Fig. 4E to $\mathrm{H}$ ). Of the remaining 30 GFP-PpECs, 12 were present in the cytoplasm and excluded from the nucleus (Fig. 4I to L), 17 were located in the nucleus and not the cytoplasm (Figure $4 \mathrm{M}$ to $\mathrm{P}$ ), and a single GFP-PpEC fusion protein was localized nearly exclusively to the nucleolus (Fig. 4Q to T). For the five GFP-PpEC fusions localized in Figure 4, we confirmed that the intact GFP-PpEC fusion proteins were expressed in $N$. benthamiana leaves, using a Western blot assay with a GFP antibody (Supplementary Fig. S2). We did not detect fluorescence signals for three of the GFP-PpEC fusion proteins in this system, suggesting that these were expressed weakly or not at all, for unknown

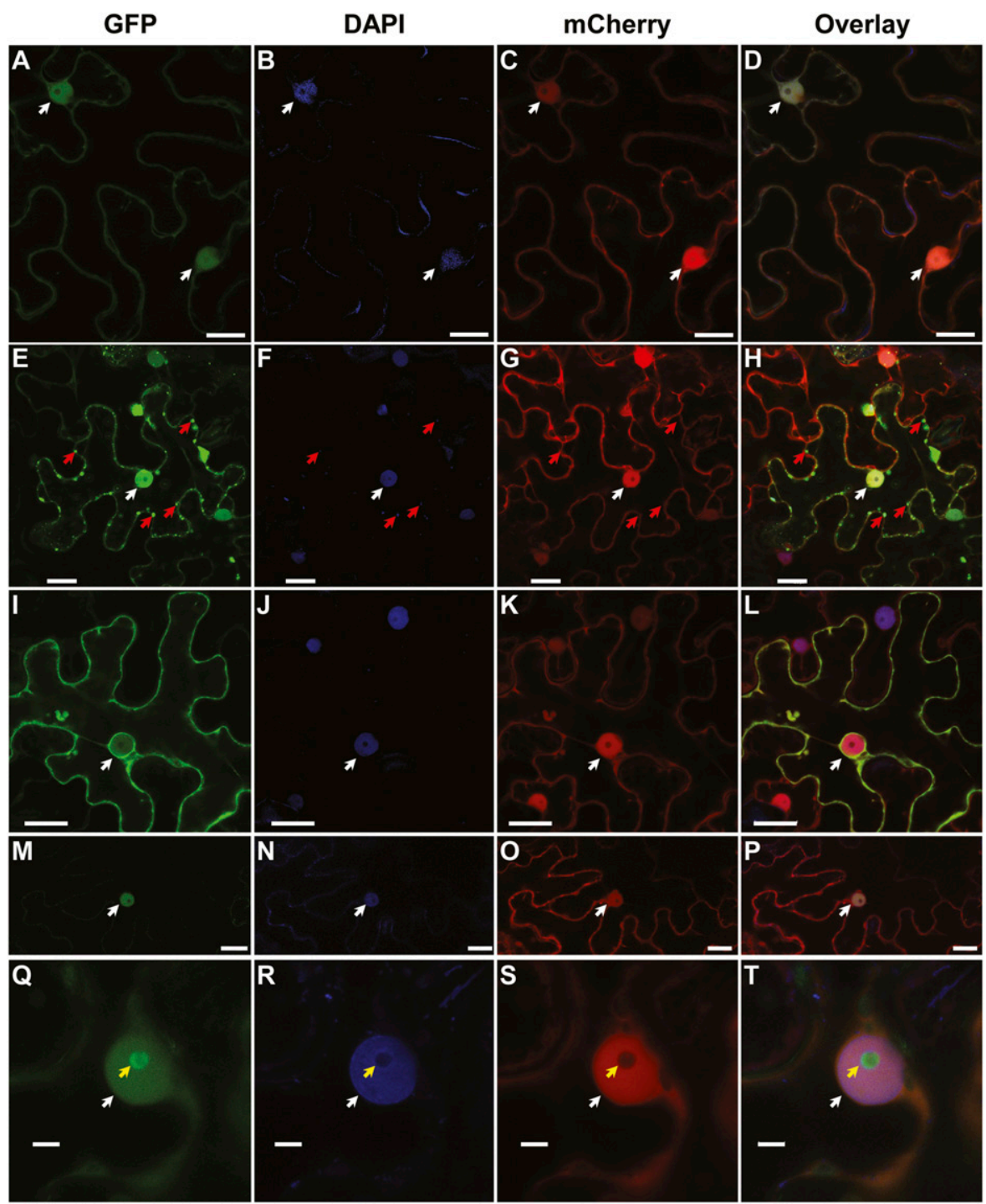

Fig. 4. Examples of in planta subcellular localization of Phakopsora pachyrhizi effector candidates (PpECs). Subcellular localizations of PpECs with an aminoterminal green fluorescent protein (GFP) fusion were determined by confocal microscopy. All GFP-PpEC fusions were transiently coexpressed with mCherry in Nicotiana benthamiana, using agroinfiltration, and leaves were stained with 4',6-diamidino-2-phenylindole (DAPI) to detect nuclei. Cells were imaged using filter sets that allowed detection of GFP, DAPI, and mCherry. A to D, PpEC49, representing localization in both the nucleus and cytoplasm. $\mathbf{E}$ to $\mathbf{H}$, PpEC81, representing localization in the nucleus and small cytoplasmic bodies. I to $\mathbf{L}$, PpEC33, representing the localization in cytoplasm only. $\mathbf{M}$ to $\mathbf{P}$, PpEC15, representing the localization in nucleus only. Q to T, PpEC10, representing localization in the nucleolus. The bar $=20 \mu \mathrm{m}$, except in Q to T, in which the bar $=5 \mu \mathrm{m}$. This assay was repeated three times. 
reasons. These findings indicate that $P$. pachyrhizi, similar to other rust fungi, may deliver effector proteins to a variety of distinct host cell compartments.

PpECs that induce HR in tomato and pepper.

We were interested in identifying nonhost plants that could express HR in response to one or more of the PpECs, as an approach to identify novel sources of resistance. In all experiments in which we infiltrated $N$. benthamiana with Pseudomonas fluorescens EtHAn or Agrobacterium strains in order to deliver the PpEC or GFP-PpEC proteins, respectively, we never observed HR. These observations suggest that none of the PpEC proteins could be recognized in $N$. benthamiana to induce a nonhost HR. To further investigate if any PpEC could induce HR in nonhost plants, we transiently expressed them in tomato (Solanum lycopersicum cv. VF36) via agroinfiltration of the GFP-PpEC constructs used for the localization experiments (Fig. 1D). GFP-PpEC6 was the only construct that induced HR in tomato in this assay (Fig. 5A).

We also used a screening system established in pepper plants for identifying effector candidates that induce nonhost HR (Fig. 1C) (Lee et al. 2014). The PpECs were cloned into the Potato virus $X$ (PVX) expression vector pYL254 (Liu et al. 2002). The PVX-PpEC clones were first agroinfiltrated into $N$. benthamiana leaves to produce infectious virions for rub-inoculation onto pepper plants (Capsicum annuum cvs. CM334 and ECW-30R). In this assay, five PpECs induced cell death in CM334 and 14 induced cell death in ECW-30R (Fig. 5). Interestingly, only two PpEC clones, PpEC9 and PpEC16, caused cell death on both
A

GFP

Negative

control

PpEC6
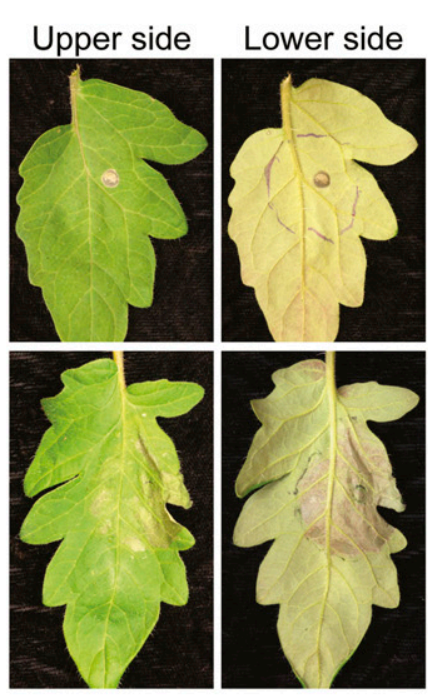

B

Avrblb2

Positive control Negative control

\section{Trypan blue} staining

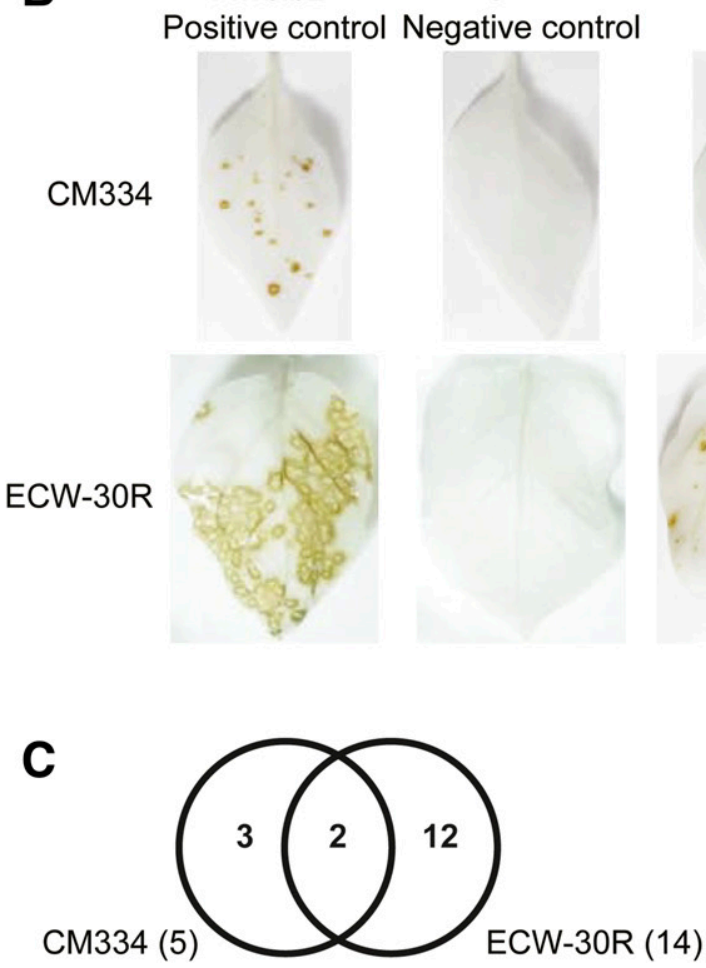



CM334 (5)

Fig. 5. Cell-death induction in tomato and pepper. A, Phakopsora pachyrhizi effector candidate 6 (PpEC6) induced cell death when transiently expressed by agroinfiltration in tomato cultivar VF36. This assay was repeated three times. B, PpEC9 and PpEC16 induced cell death in pepper cultivars ECW-30R and CM334 when expressed from Potato virus X. C, The Venn diagram displays the number of PpECs inducing cell death in pepper cultivars CM334 and ECW$30 \mathrm{R}$, with the total number shown in parentheses. 
pepper cultivars, suggesting that there is a common mechanism for recognizing them in these two cultivars. These findings also indicate that there is differential recognition of several PpEC proteins by the pepper immune system.

\section{DISCUSSION}

Our goal was to use a variety of approaches that enabled relatively large-scale screens of $P$. pachyrhizi haustoria-expressed secreted proteins, which we previously termed PpECs, for functions expected of effectors. Toward this end, we cloned the ORFs minus signal peptide of 82 PpECs from isolate LA04-1 of $P$. pachyrhizi into a Gateway entry vector and re-sequenced them. The ORFs were readily mobilized from the entry vector into four different vectors for expression in bacteria, plants, and yeast, namely, pEDV6 (bacterial T3S signal fused to amino termini), pSITEII3C1 (T-DNA vector for in planta expression of N-terminal GFP fusions), pYL254 (transient in planta expression from PVX), and pGBKT7-GW (constitutive expression in yeast with $\mathrm{N}$ terminal Gal4 binding domain fusions). These vectors enabled a variety of assays in $N$. benthamiana, $N$. tabacum, A. thaliana, soybean, tomato, pepper, and yeast that allowed us to associate 17 PpECs with activities consistent with immune suppression in planta (Table 1), 18 PpECs with activities suggesting immune activation in nonhosts, and 54 PpECs that suppressed BAX-induced cell death to various extents in yeast.

The identification of effectors from rusts and other fungi is complicated by the fact that there are, as yet, no tell-tale signatures that enable prediction of effector proteins with high confidence (Bakkeren et al. 2016). This is in contrast with bacterial and oomycete pathogens for which T3S signals and RxLR or CRINKLER motifs, respectively, can be used to reliably identify effector proteins. Nevertheless, several groups have developed bioinformatic pipelines for predicting rust effector candidates from genomes, transcriptomes, or both (Bakkeren et al. 2016; Lorrain et al. 2015; Petre et al. 2014; Sperschneider et al. 2016). Characteristics that are used in some or all these pipelines include i) the presence of a signal peptide and no other targeting sequence or transmembrane domain, ii) size of the predicted protein $<300$ aa, iii) no annotation for predicted protein, iv) lineage specificity (e.g., not found outside of order Pucciniales), v) high cysteine content, vi) expression in haustoria or at least in planta, and vii) signatures of rapid evolution. Following these analyses, a few hundred to several hundred candidate effector proteins remain, creating a new problem of how to prioritize them for further analyses (Petre et al. 2014). Programs such as EffectorP and LOCALIZER were developed to refine predictions about proteins most likely to share common features with known effectors or to be localized to an interesting compartment within the target host cell (Sperschneider et al. 2016, 2017).

Despite some limitations to predict the full complement of $P$. pachyrhizi secreted proteins, there are still plenty of candidates to choose from, creating the need for a large-scale effectoromics approach. To discover $P$. pachyrhizi effectors, we used the 156 PpECs identified by Link et al. (2014) as our starting point, making no assumption about protein size, annotation, lineage specificity, cysteine content, or signatures of rapid evolution. Instead, we elected to cast a wide net by using assays that allowed us to screen a relatively large number of PpECs for effector-like functions and their localizations. The 82 cloned PpEC ORFs ranged in size from 89 to 684 aa, and, although we did not use a size cut-off, 62 of these PpECs were smaller than 300 aa, reflecting an inherent bias toward smaller proteins. We included the larger PpECs because some known effectors, such as AvrM, are larger than 300 aa (Petre et al. 2014). Arguments for including proteins with functional annotation comes from examples of effectors identified in other plant-pathogenic fungi, such as BEC1019, a CSEP from the barley powdery mildew pathogen, or Cmul from
Ustilago maydis. BEC1019 is a broadly conserved protein that is present in pathogenic and nonpathogenic fungi, it suppresses host cell death and is required for full virulence (Whigham et al. 2015). Cmu1 is a chorismate mutase, an enzyme that can be found in other microbial pathogens and in plant-parasitic nematodes (Gao et al. 2003; Huang et al. 2005; Noon and Baum 2016). It is required for full $U$. maydis virulence (Djamei et al. 2011). Only 12 of our PpECs possessed functional annotation, indicating an inherent bias toward unannotated proteins.

Our strategies to screen the $82 \mathrm{PpECs}$ for effector-like functions and localization relied heavily on heterologous plants and effector delivery systems for several reasons. From the plant perspective, all assays involving bacterial delivery (Pseudomonas spp. or Agrobacterium tumefaciens) require consistent and reproducible infiltration of the leaves, which is difficult on this scale in soybean. Therefore, we relied primarily on $N$. benthamiana, for many of the initial assays, because its leaves are very easy to infiltrate. The use of heterologous plant systems may raise concerns that the same functions may not be observed in the host plant. However, evidence is accumulating that validates such effector screens. In the case of PpEC23, we have previously shown that the immune suppression functions in Nicotiana spp. also occur in soybean (Qi et al. 2016). PpEC23 suppresses HR caused by Pseudomonas syringae pv. tomato DC3000 in soybean, $N$. benthamiana, and N. tabacum, although a different effector-resistance gene pair is responsible for activating $\mathrm{HR}$ in soybean and Nicotiana spp. These immune suppression functions may occur through interaction with a transcription factor belonging to the SQUAMOSA PROMOTERBINDING-LIKE (SPL) family (Qi et al. 2016). PpEC23 was also tested by Kunjeti et al. (2016) (CSEP-35) for an ability to promote Phytophthora infestans virulence on $N$. benthamiana, but no effect was observed. However, they did observe that transient expression of CSEP-07 and CSEP-09 promoted Phytophthora infestans growth. CSEP-07 was not among our cloned PpECs, but CSEP09 corresponds to PpEC59, which did not alter plant immune responses in the assays we performed. None of the six effector candidates shown by de Carvalho et al. (2017) to suppress Pseudomonas syringae pv. tomato DC3000-induced HR were among our cloned PpECs, but interestingly, PpEC23 shares a tencysteine motif with three of the effector candidates that were members of their Tribe 3 . This observation provides additional evidence that the family of candidate effectors including PpEC23 play important roles in $P$. pachyrhizi virulence.

Puccinia striiformis f. sp. tritici effector candidate PEC6 compromises PTI in N. benthamiana, A. thaliana, and wheat (Liu et al. 2016). PEC6 was one of six randomly selected effector candidates that possess a signal peptide and are highly expressed in haustoria. Host-induced gene silencing (HIGS) to downregulate expression of PEC6 decreased the number of Puccinia striiformis f. sp. tritici pustules, further supporting its role in virulence. Another Puccinia striiformis $\mathrm{f}$. sp. tritici effector candidate, PSTha5a23, suppresses cell death induced by BAX, INF1, MKK1, and NPK1 in N. benthamiana (Cheng et al. 2017). HIGS of PSTha5a23 had no effect on fungal growth, but its overexpression in wheat plants suppressed callose deposition associated with PTI and promoted fungal infection. This effector candidate was selected for analysis because it was unique to Puccinia striiformis f. sp. tritici, exhibited a low level of intraspecies polymorphism, and had high expression in planta. Shr7, also from Puccinia striiformis f. sp. tritici, was identified as one of nine effector candidates that suppress ETI in $N$. benthamiana out of a total of 18 candidate effectors screened (Ramachandran et al. 2017). Shr7 was unique among these nine effector candidates in its ability to also suppress flg22-induced ROS production. When Shr7 was introduced into wheat, using the Pseudomonas fluorescens EtHAn strain, it was also observed to suppress HR that is normally induced by Pseudomonas syringae pv. tomato DC3000. 
Although the $P$. pachyrhizi host range is limited to legumes (Goellner et al. 2010), 17 PpECs could suppress immunity in $N$. benthamiana and A. thaliana. One reason why functions for some effectors may be observed in heterologous plants is that effectors encoded by organisms as different as bacterial and oomycete pathogens converge on a limited set of host target proteins (Mukhtar et al. 2011). This suggests that there are conserved components of plant immune protein networks that are important targets for diverse pathogens. It is not unexpected that we were unable to detect an effector-like function for 65 of the PpECs. Possible reasons for this include a requirement for specific interaction between PpECs and one or more of their host targets, artifacts of expression (e.g., misfolding, mislocalization, addition of GFP or epitope tags, presence of Gateway linkers, lack of posttranslational modifications that would be added in the fungus, or improper timing), inappropriate defense suppression, or activation assay, or they may possess other functions related to pathogenicity and virulence, such as nutrient acquisition, that we did not test for or some may not be bona fide effectors. Another interesting possibility is that the activity of some effectors may be influenced by others (Ma et al. 2017; Wei et al. 2015), which we could not test by expressing the PpECs individually.

Besides immune suppression, we were also interested in the ability of PpECs to activate plant immune responses, particularly in nonhost plants. Other groups have focused on understanding factors that contribute to nonhost resistance to $P$. pachyrhizi in $A$. thaliana and Medicago sativa (Campe et al. 2016; Ishiga et al. 2015; Langenbach et al. 2013; Loehrer et al. 2008). We tested whether any PpEC could induce HR in tomato cultivar VF36 and pepper cultivars CM334 and ECW-30R. PpEC6 induced HR in tomato and it also suppressed basal defense to Pseudomonas fluorescens EtHAn in $N$. benthamiana and callose deposition in A. thaliana. Although PpEC6 was identified in our original bioinformatic analyses as a potentially secreted protein, closer inspection of its amino acid sequence indicates that it possesses a C-terminal HDEL motif that could cause it to be retained in the fungal endoplasmic reticulum (Pelham et al. 1988). Therefore, we have elected not to further pursue its characterization. In pepper, $17 \mathrm{PpECs}$ induced $\mathrm{HR}$ in at least one cultivar, but there were only two PpECs that induced HR in both cultivars. Interestingly, these two PpECs also suppressed PTI responses, whereas only one of the 15 PpECs that induced cultivar-specific HR in pepper also suppressed PTI responses. These data suggest that there is specificity for recognizing the presence of PpECs in pepper, and these differential responses could be useful in the future for mapping and cloning potentially new soybean rust resistance genes. In a previous study, 36 of 54 RXLR effectors from Phytophthora infestans caused HR in at least a subset of 100 pepper cultivars screened by agroinfiltration, and, of these, pepper responses were verified for 17, using the PVX expression system in a subset of four cultivars (Lee et al. 2014). Some pepper genotypes were able to broadly recognize RXLR effectors, while others were more specific. Genetic analyses indicated that the responses segregated in ratios consistent with recognition of effectors by one or two dominant genes. Some secreted proteins may also induce immune responses similar to PTI. Puccinia striiformis f. sp. trititici effector candidate PSTha2a5 (PstSCR1) activated immunity when expressed in $N$. benthamiana. This induced immunity required the signal peptide and the plant coreceptor protein BAK1, and it reduced infection by Phytophthora infestans and Peronospora hyoscyami f. sp. tabacina (Dagvadorj et al. 2017). Because the signal peptide was removed in our assays, we would not have been able to identify immune activation at the cell surface.

Yeast is amenable to high throughput screens, and hallmarks of cell death are conserved among yeast and plants (Chen et al. 2004). We tested for the ability of PpECs to suppress BAX-induced cell death. BAX is a mammalian proapoptotic protein that interferes with yeast mitochondrial functions and causes ROS accumulation and cell death (Priault et al. 2003), which bears similarity to HR in plants (Lacomme and Santa Cruz 1999). We reasoned that studying cell death suppression in yeast could lead to insights into effector function and immune suppression in plants. AvrPtoB is an example of a bacterial type III effector that functions across kingdoms by suppressing cell death in both plants and yeast (Abramovitch et al. 2003). The Avr1b and Avh331 RXLR effectors from Phytophthora sojae can weakly suppress BAX-induced cell death in yeast (Wang and Huang 2011). Here, a surprising number of PpECs could suppress BAX-induced cell death to one extent or another and, as such, it is currently difficult to interpret our results. If we focus on the strong suppressors of BAX-induced cell death, which are all well under 300 aa, then PpEC49 and PpEC82 stand out, because they also are strong suppressors of PTI responses. It would be interesting to test if randomly selected proteins with similar properties but not predicted to be secreted could suppress BAX-induced cell death to a similar extent, but this would require considerable effort and time. Nevertheless, these results suggest that yeast could be a suitable system in which to explore the mechanisms of PpEC function in the future.

\section{Concluding remarks.}

The current challenges of determining the functions of effectors produced by obligate biotrophic fungi have necessitated approaches using heterologous plants and expression systems. The use of bacterial, viral, and yeast expression systems and nonhost plants (i.e., $N$. benthamiana, $N$. tabacum, A. thaliana, tomato, and pepper) enabled us to interrogate PpECs on a relatively large scale. Previous work by ourselves and others demonstrates that studies initiated in surrogate systems can often translate directly to the functions of effector proteins in the crop host. The 17 PpECs that suppress PTI coupled with insight into their potential localizations form an important foundation for future studies geared toward understanding how $P$. pachyrhizi and, potentially, other rusts colonize their hosts. The properties of these 17 PpECs demonstrates that if our assays had been biased toward small proteins high in cysteine content and lacking functional annotation, we would have ignored several potentially interesting PpECs. These PpECs are good targets for HIGS studies, to determine their roles in pathogenicity, expression in soybean, identification of one or more host protein targets, biochemical characterization, and more detailed localization analyses during fungal infections. The screens performed are not exhaustive and, therefore, we are also interested in employing other types of assays that can provide insight into other facets of effector functions that influence $P$. pachyrhizi pathogenicity and virulence.

\section{MATERIALS AND METHODS}

\section{Bacterial strain and plasmid mobilizations.}

Bacterial strains used in this study are listed in Table 2. Escherichia coli and Agrobacterium tumefaciens were grown in Luria-Bertani (LB) broth at $37^{\circ} \mathrm{C}\left(\right.$ E. coli) or $28^{\circ} \mathrm{C}$ (Agrobacterium tumefaciens), using either liquid or solid media. Pseudomonas strains were grown in either LB or King's B (KB) medium at $28^{\circ} \mathrm{C}$. Plasmids were mobilized from E. coli to Pseudomonas strains by standard triparental mating using E. coli HB101 (pRK2013) as a helper strain.

\section{Plant materials.}

N. benthamiana, N. tabacum cv. Xanthi, soybean (Glycine max cv. Williams 82), tomato (Solanum lycopersicum cv. VF36), and pepper (Capsicum annuum cv. CM334 and ECW30R) plants were grown in controlled environment chambers at an average temperature of $24^{\circ} \mathrm{C}$ (range 20 to $26^{\circ} \mathrm{C}$ ), with 45 to $65 \%$ relative humidity under long-day conditions ( $16 \mathrm{~h}$ of light). A. thaliana plants were grown in controlled environment chambers 
at an average temperature of $22^{\circ} \mathrm{C}$ (range 18 to $24^{\circ} \mathrm{C}$ ), with 45 to $65 \%$ relative humidity under short-day conditions (10 h of light).

\section{Cloning PpEC ORFs from the LA04-1 isolate of $P$. pachyrhizi.}

Leaf tissue was collected from cv. Williams 82 soybean plants 7 dpi with $P$. pachyrhizi isolate LA04-1 (Baysal-Gurel et al. 2008) and were immediately frozen in liquid nitrogen and were stored at $-80^{\circ} \mathrm{C}$. Infected leaf tissue was ground in liquid nitrogen and RNA was extracted, using the Qiagen plant RNeasy kit (Qiagen, Valencia, CA, U.S.A.), and was treated with Turbo DNase (Ambion, Thermo Fisher Scientific, Waltham, MA, U.S.A.). Complementary DNA (cDNA) was synthesized using oligo dT primer and Superscript III reverse transcription according to the manufacturer's protocol (Invitrogen, Carlsbad, CA, U.S.A.). The PpEC ORFs were PCR amplified from the cDNA of $P$. pachyrhizi isolate LA04-1 without signal peptide. The PCR products were cloned into the Gateway entry vector $\mathrm{pCR} 8 / \mathrm{GW} / \mathrm{TOPO}$ (Invitrogen).

\section{Bacterial inoculation and growth in planta.}

Nicotiana plants used in this study were between five and six weeks old, A. thaliana plants were between four and five weeks old, tomato plants were four weeks old, and soybean plants were 14 days old. For expression of PpECs via the bacterial T3SS, the PpEC ORFs were recombined into the Gateway destination vector pEDV6 (Table 2), using LR clonase II (Invitrogen). All plant assays were performed by infiltrating a bacterial suspension into plant leaves with a needleless syringe. Agrobacterium strains were resuspended in the induction buffer $(100 \mu \mathrm{M}$ acetosyringone, $10 \mathrm{mM}$ MES, $\mathrm{pH} 5.6$, and $10 \mathrm{mM} \mathrm{MgCl}$ ) and were kept at room temperature for $3 \mathrm{~h}$ before infiltration, all other strains were resuspended in inoculation buffer $(10 \mathrm{mM} \mathrm{MgCl} 2)$. The areas of bacterial infiltration were marked lightly with a Sharpie permanent marker. Levels of bacterial inoculum used in experiments are noted in the figures and legends. Bacterial levels in planta were determined by cutting leaf disks with a cork borer (inner diameter $0.5 \mathrm{~cm}$ ) and completely homogenizing them in $500 \mu \mathrm{l}$ of inoculation buffer. The resulting suspension containing the bacteria was diluted and plated on $\mathrm{KB}$ plates with appropriate antibiotics.

\section{Callose staining and microscopic analysis.}

A. thaliana leaves were harvested $12 \mathrm{~h}$ after bacterial infiltration and were cleared and stained with aniline blue for callose, as described (Adam and Somerville 1996). Leaves were examined with a Zeiss Axioplan II microscope with an A4 fluorescence cube. The numbers of callose deposits were determined with ImageJ software (NIH). Six adjacent fields of view along the length of the leaf (avoiding the midvein, leaf edge, or the syringedamaged area) were analyzed and averaged. The values shown in Figure $2 \mathrm{~F}$ are the average and standard deviation of more than six independent leaves for each treatment.

\section{Agroinfiltration-mediated transient expression in $N$. benthamiana and PVX inoculation of pepper.}

To create GFP-PpEC constructs, the PpEC ORFs cloned into the Gateway entry vector $\mathrm{pCR} 8 / \mathrm{GW} / \mathrm{TOPO}$ were recombined into the Gateway binary destination vector pSITEII-3C1 (Table 2), using LR clonase II (Invitrogen). To create PVX-PpEC constructs, the same set of PpEC ORFs without signal peptides were inserted into pYL254. All binary vectors were introduced into Agrobacterium tumefaciens GV3101 using the freeze-thaw method (An et al. 1988). GFP was detected in agroinfiltrated $N$. benthamiana leaves using a Leica SP5 X MP confocal/multiphoton microscope system at $48 \mathrm{~h}$ after infiltration. PVX-PpEC-infected systemic $N$. benthamiana leaves after agroinfiltration were collected, ground, and rub-inoculated with 400-mesh Carborundum on pepper

Table 2. Strains and plasmids

\begin{tabular}{|c|c|c|}
\hline Strain or plasmid & Genotype or relevant phenotype ${ }^{a}$ & Source or reference \\
\hline \multicolumn{3}{|l|}{ Escherichia coli } \\
\hline DH5 $\alpha$ & $\begin{array}{l}\mathrm{F}^{-} \text {end } \mathrm{A} 1 \text { glnV44 thi-1 rec } \mathrm{A} 1 \text { relA1 gyrA96 } \\
\text { deo } \mathrm{R} \text { nupG } \Phi 80 \mathrm{~d} l a c Z \Delta \mathrm{M} 15 \Delta(\text { lacZYA- } \\
\text { argF }) \mathrm{U} 169 h s d \mathrm{R} 17\left(\mathrm{r}_{\mathrm{K}}^{-} \mathrm{m}_{\mathrm{K}}^{+}\right) \lambda^{-}\end{array}$ & Invitrogen \\
\hline TOP10 &  & Invitrogen \\
\hline \multicolumn{3}{|c|}{ Pseudomonas syringae pv. tomato } \\
\hline DC3000 & Wild type, Rif ${ }^{\mathrm{T}}$ & S. Y. He lab \\
\hline CUCPB5115 & $\Delta C E L:: \Omega S p / \mathrm{Sm}^{\mathrm{r}}, \mathrm{Rif}^{\mathrm{r}} \mathrm{Sp}^{\mathrm{r}}$ & Badel et al. 2003 \\
\hline \multicolumn{3}{|c|}{ Pseudomonas fluorescens } \\
\hline EtHAn & $\begin{array}{l}\text { Pseudomonas fluorescens } \text { Pf0-1 carrying a } \\
\text { working TTSS from Pseudomonas syringae } \\
\text { pv. syringae, } \mathrm{Cm}^{\mathrm{r}}\end{array}$ & Thomas et al. 2009 \\
\hline \multicolumn{3}{|c|}{ Agrobacterium tumefaciens } \\
\hline GV3101 & $\begin{array}{l}\text { Carries Vir plasmid encoding T-DNA } \\
\text { transfer machinery, } \text { Rif }^{\mathrm{r}}, \mathrm{Gm}^{\mathrm{r}}\end{array}$ & Lab stock \\
\hline \multicolumn{3}{|c|}{ Saccharomyces cerevisiae } \\
\hline BF264-15Dau & MAT $\alpha$ ade1 his2 leu2-3,112trp1-1a ura3 & M. G. Mitchum lab \\
\hline \multicolumn{3}{|l|}{ Plasmids } \\
\hline pCR8/GW/TOPO & Gateway-compatible entry vector, $\mathrm{Sp}^{\mathrm{r}}$ & Invitrogen \\
\hline pEDV6 & Gateway-compatible version of pEDV $3, \mathrm{Gm}^{\mathrm{r}}$ & Sohn et al., 2007 \\
\hline pGBKT7-GW & Gateway-compatible version of pGBKT7, $\mathrm{Km}^{\mathrm{r}}$ & M. G. Mitchum lab \\
\hline pYEp51-bax & $\begin{array}{l}\text { bax expression controlled by GAL10 } \\
\text { promoter, Amp }{ }^{\mathrm{r}} \text {, LEU2 }\end{array}$ & M. G. Mitchum lab \\
\hline pSITEII-3C1 & $\begin{array}{l}\text { Gateway-compatible binary vector for } \\
\text { transient overexpression of enhanced green } \\
\text { fluorescent protein-fused in planta, } \mathrm{Sp}^{\mathrm{r}}\end{array}$ & Martin et al., 2009 \\
\hline pYL254 & $\begin{array}{l}\text { Gateway-compatible Potato virus } X \text {-based } \\
\text { expression vector, } \mathrm{Km}^{\mathrm{r}}\end{array}$ & Liu et al. 2002 \\
\hline
\end{tabular}

\footnotetext{
${ }^{a}$ Antibiotics were used at the following concentrations ( $\left.\mu \mathrm{g} / \mathrm{ml}\right)$ : rifampicin (Rif) 100, gentamycin (Gm) 50, kanamycin (Km) 100, spectinomycin (Sp) 50, chloramphenicol (Cm) 30, and ampicillin (Amp) 100.
} 
leaves. At 7 to $8 \mathrm{dpi}$, inoculated leaves were harvested and characterized for cell-death phenotypes by destaining chlorophyll with $100 \%$ ethanol for 3 to 5 days.

\section{Yeast cell-death assays.}

Yeast cell-death assays were performed following the procedure previously described (Laloux et al. 2010), with some modifications. Yeast strain BF264-15Dau carrying the plasmid YEp51-bax, which is inducible by galactose to express BAX protein, and Gateway-compatible pGBKT7-GW containing PpEC ORFs was cultured in liquid SD/-Leu/-Trp media at $30^{\circ} \mathrm{C}$ for overnight before the yeast cells were resuspended in liquid YNB/Gal/-Leu/-Trp media (yeast nitrogen base $6.7 \mathrm{~g}$ per liter, galactose $2 \%$, -Leu/-Trp DO supplement $0.64 \mathrm{~g}$ per liter) for 6-h induction. Yeast cells were collected by centrifugation, were washed in liquid YNB/Gal/-Leu/-Trp media for at least four times and were adjusted to an optical density at $600 \mathrm{~nm}$ of 1 . The resulting yeast inoculum was serially diluted and was placed on YNB/Gal/ -Leu/-Trp plate. The plates were photographed on the fourth day after culturing at $30^{\circ} \mathrm{C}$. Nematode effector $4 \mathrm{~F} 01$ (M. G. Mitchum, personal communication) and empty vector were included in each plate as positive and negative control, respectively.

\section{ACKNOWLEDGMENTS}

We thank J. Aker and J. Hanna (National Science Foundation [NSF] Research Experience for Teachers interns) for assisting with the $N$. benthamiana ETI suppression of basal defense screens. We thank J. McDowell for supplying Pseudomonas fluorescens and pEDV6 and M. G. Mitchum for sharing the yeast strain, plasmids, and the soybean cyst nematode effector 4F01. This work was supported by the Iowa Soybean Association, NSF IOS (award 1551452 to SAW), NSF Plant Genome Research Program (award number 0820642 to S. A. Whitham and T. J. Baum), United States Department of Agriculture National Institute of Food and Agriculture Hatch project 3808, and State of Iowa funds. R. T. Voegele, T. I. Link, and J. M. Seitz were supported by a PPP program of the Deutscher Akademischer Austauschdienst (PPP 57130080).

\section{LITERATURE CITED}

Abramovitch, R. B., Kim, Y. J., Chen, S., Dickman, M. B., and Martin, G. B. 2003. Pseudomonas type III effector AvrPtoB induces plant disease susceptibility by inhibition of host programmed cell death. EMBO J. 22:60-69.

Adam, L., and Somerville, S. C. 1996. Genetic characterization of five powdery mildew disease resistance loci in Arabidopsis thaliana. Plant J. 9:341-56.

Ade, J., DeYoung, B. J., Golstein, C., and Innes, R. W. 2007. Indirect activation of a plant nucleotide binding site-leucine-rich repeat protein by a bacterial protease. Proc. Natl. Acad. Sci. U.S.A. 104:2531-2536.

An, G., Ebert, P. R., Mitra, A., and Ha, S. B. 1988. Binary vectors. Pages 1-19 in: Plant Molecular Biology Manual. Kluwer Academic Publishers, Dordrecht, The Netherlands.

Badel, J. L., Nomura, K., Bandyopadhyay, S., Shimizu, R., Collmer, A., and He, S. Y. 2003. Pseudomonas syringae pv. tomato DC3000 HopPtoM (CEL ORF3) is important for lesion formation but not growth in tomato and is secreted and translocated by the Hrp type III secretion system in a chaperone-dependent manner. Mol. Microbiol. 49:1239-1251.

Bakkeren, G., Joly, D. L., and Duplessis, S. 2016. Editorial: Genomics research on non-model plant pathogens: Delivering novel insights into rust fungus biology. Front. Plant Sci. 7:216.

Baysal-Gurel, F., Ivey, M. L. L., Dorrance, A., Luster, D., Frederick, R., Czarnecki, J., Boehm, M., and Miller, S. A. 2008. An immunofluorescence assay to detect urediniospores of Phakopsora pachyrhizi. Plant Dis. 92:1387-1393.

Campe, R., Langenbach, C., Leissing, F., Popescu, G. V., Popescu, S. C., Goellner, K., Beckers, G. J., and Conrath, U. 2016. ABC transporter PEN3/PDR8/ABCG36 interacts with calmodulin that, like PEN3, is required for Arabidopsis nonhost resistance. New Phytol. 209:294-306.

Cantu, D., Segovia, V., MacLean, D., Bayles, R., Chen, X., Kamoun, S. Dubcovsky, J., Saunders, D. G. O., and Uauy, C. 2013. Genome analyses of the wheat yellow (stripe) rust pathogen Puccinia striiformis f. $\mathrm{sp}$. tritici reveal polymorphic and haustorial expressed secreted proteins as candidate effectors. BMC Genomics 14:270.

Catanzariti, A.-M., Dodds, P. N., and Ellis, J. G. 2007. Avirulence proteins from haustoria-forming pathogens. FEMS Microbiol. Lett. 269:181-188.
Chen, S., Vaghchhipawala, Z., Li, W., Asard, H., and Dickman, M. B. 2004 Tomato phospholipid hydroperoxide glutathione peroxidase inhibits cell death induced by Bax and oxidative stresses in yeast and plants. Plant Physiol. 135:1630-1641.

Cheng, Y., Wu, K., Yao, J., Li, S., Wang, X., Huang, L., and Kang, Z. 2017. PSTha5a23, a candidate effector from the obligate biotrophic pathogen Puccinia striiformis f. sp. tritici, is involved in plant defense suppression and rust pathogenicity. Environ. Microbiol. 19:1717-1729.

Chisholm, S. T., Coaker, G., Day, B., and Staskawicz, B. J. 2006. Hostmicrobe interactions: shaping the evolution of the plant immune response. Cell 124:803-814.

Dagvadorj, B., Ozketen, A. C., Andac, A., Duggan, C., Bozkurt, T. O., and Akkaya, M. S. 2017. A Puccinia striiformis f. sp. tritici secreted protein activates plant immunity at the cell surface. Sci. Rep. 7:1141

Dangl, J. L., Horvath, D. M., and Staskawicz, B. J. 2013. Pivoting the plant immune system from dissection to deployment. Science 341:746-751.

de Carvalho, M. C., Costa Nascimento, L., Darben, L. M., PolizelPodanosqui, A. M., Lopes-Caitar, V. S., Qi, M., Rocha, C. S., Carazzolle, M. F., Kuwahara, M. K., Pereira, G. A., Abdelnoor, R. V., Whitham, S. A., and Marcelino-Guimaraes, F. C. 2017. Prediction of the in planta Phakopsora pachyrhizi secretome and potential effector families. Mol. Plant Pathol. 18:363-377.

DebRoy, S., Thilmony, R., Kwack, Y. B., Nomura, K., and He, S. Y. 2004. A family of conserved bacterial effectors inhibits salicylic acidmediated basal immunity and promotes disease necrosis in plants. Proc. Natl. Acad. Sci. U.S.A. 101:9927-9932.

Djamei, A., Schipper, K., Rabe, F., Ghosh, A., Vincon, V., Kahnt, J., Osorio, S., Tohge, T., Fernie, A. R., Feussner, I., Feussner, K., Meinicke, P., Stierhof, Y. D., Schwarz, H., Macek, B., Mann, M., and Kahmann, R. 2011. Metabolic priming by a secreted fungal effector. Nature 478:395-398.

Dodds, P. N., and Rathjen, J. P. 2010. Plant immunity: Towards an integrated view of plant-pathogen interactions. Nat. Rev. Genet. 11:539-548.

Dou, D., and Zhou, J. M. 2012. Phytopathogen effectors subverting host immunity: Different foes, similar battleground. Cell Host Microbe 12: 484-495.

Fabro, G., Steinbrenner, J., Coates, M., Ishaque, N., Baxter, L., Studholme, D. J., Körner, E., Allen, R. L., Piquerez, S. J. M., Rougon-Cardoso, A. Greenshields, D., Lei, R., Badel, J. L., Caillaud, M.-C., Sohn, K.-H., Van den Ackerveken, G., Parker, J. E., Beynon, J., and Jones, J. D. G. 2011 Multiple candidate effectors from the oomycete pathogen Hyaloperonospora arabidopsidis suppress host plant immunity. PLoS Pathog. 7:e1002348.

Gao, B., Allen, R., Maier, T., Davis, E. L., Baum, T. J., and Hussey, R. S. 2003. The parasitome of the phytonematode Heterodera glycines. Mol. Plant-Microbe Interact 16:720-726.

Germain, H., Joly, D. L., Mireault, C., Plourde, M. B., Letanneur, C., Stewart, D., Morency, M. J., Petre, B., Duplessis, S., and Seguin, A. 2016. Infection assays in Arabidopsis reveal candidate effectors from the poplar rust fungus that promote susceptibility to bacteria and oomycete pathogens. Mol. Plant Pathol. Published online.

Gill, U. S., Lee, S., and Mysore, K. S. 2015. Host versus nonhost resistance: Distinct wars with similar arsenals. Phytopathology 105:580-587.

Glazebrook, J. 2005. Contrasting mechanisms of defense against biotrophic and necrotrophic pathogens. Annu. Rev. Phytopathol. 43:205-227.

Goellner, K., Loehrer, M., Langenbach, C., Conrath, U., Koch, E., and Schaffrath, U. 2010. Phakopsora pachyrhizi, the causal agent of Asian soybean rust. Mol. Plant Pathol. 11:169-177.

Huang, G., Dong, R., Allen, R., Davis, E. L., Baum, T. J., and Hussey, R. S. 2005. Two chorismate mutase genes from the root-knot nematode Meloidogyne incognita. Mol. Plant Pathol. 6:23-30.

Ishiga, Y., Uppalapati, S. R., Gill, U. S., Huhman, D., Tang, Y., and Mysore, K. S. 2015. Transcriptomic and metabolomic analyses identify a role for chlorophyll catabolism and phytoalexin during Medicago nonhost resistance against Asian soybean rust. Sci. Rep. 5:13061.

Jones, J. D., and Dangl, J. L. 2006. The plant immune system. Nature 444: 323-329.

Kamoun, S. 2007. Groovy times: Filamentous pathogen effectors revealed. Curr. Opin. Plant Biol. 10:358-365.

Kobayashi, D. Y., Tamaki, S. J., and Keen, N. T. 1989. Cloned avirulence genes from the tomato pathogen Pseudomonas syringae pv. tomato confer cultivar specificity on soybean. Proc. Natl. Acad. Sci. U.S.A. 86:157-161.

Kunjeti, S. G., Iyer, G., Johnson, E., Li, E., Broglie, K. E., Rauscher, G., and Rairdan, G. J. 2016. Identification of Phakopsora pachyrhizi candidate effectors with virulence activity in a distantly related pathosystem. Front. Plant Sci. 7:269.

Lacomme, C., and Santa Cruz, S. 1999. Bax-induced cell death in tobacco is similar to the hypersensitive response. Proc. Natl. Acad. Sci. U.S.A. 96:7956-7961. 
Laloux, G., Deghelt, M., de Barsy, M., Letesson, J. J., and De Bolle, X 2010. Identification of the essential Brucella melitensis porin Omp2b as a suppressor of Bax-induced cell death in yeast in a genome-wide screening. PLoS One 5:e13274.

Langenbach, C., Campe, R., Schaffrath, U., Goellner, K., and Conrath, U. 2013. UDP-glucosyltransferase UGT84A2/BRT1 is required for Arabidopsis nonhost resistance to the Asian soybean rust pathogen Phakopsora pachyrhizi. New Phytol. 198:536-545.

Lee, H. A., Kim, S. Y., Oh, S. K., Yeom, S. I., Kim, S. B., Kim, M. S., Kamoun, S., and Choi, D. 2014. Multiple recognition of RXLR effectors is associated with nonhost resistance of pepper against Phytophthora infestans. New Phytol. 203:926-938.

Link, T. I., Lang, P., Scheffler, B. E., Duke, M. V., Graham, M. A., Cooper, B., Tucker, M. L., van de Mortel, M., Voegele, R. T., Mendgen, K., Baum, T. J., and Whitham, S. A. 2014. The haustorial transcriptomes of Uromyces appendiculatus and Phakopsora pachyrhizi and their candidate effector families. Mol. Plant Pathol. 15:379-393.

Liu, C., Pedersen, C., Schultz-Larsen, T., Aguilar, G. B., Madriz-Ordenana, K., Hovmoller, M. S., and Thordal-Christensen, H. 2016. The stripe rust fungal effector PEC6 suppresses pattern-triggered immunity in a host species-independent manner and interacts with adenosine kinases. New Phytol. Published online. https://doi.org/10.1111/nph.14034

Liu, Y., Schiff, M., Serino, G., Deng, X. W., and Dinesh-Kumar, S. P. 2002. Role of SCF ubiquitin-ligase and the COP9 signalosome in the $N$ gene-mediated resistance response to Tobacco mosaic virus. Plant Cell 14:1483-1496.

Loehrer, M., Langenbach, C., Goellner, K., Conrath, U., and Schaffrath, U. 2008. Characterization of nonhost resistance of Arabidopsis to the Asian soybean rust. Mol. Plant-Microbe Interact 21:1421-1430.

Loehrer, M., Vogel, A., Huettel, B., Reinhardt, R., Benes, V., Duplessis, S., Usadel, B., and Schaffrath, U. 2014. On the current status of Phakopsora pachyrhizi genome sequencing. Front. Plant Sci. 5:377.

Lorrain, C., Hecker, A., and Duplessis, S. 2015. Effector-mining in the poplar rust fungus Melampsora larici-populina secretome. Front. Plant Sci. 6:1051.

Ma, Z., Zhu, L., Song, T., Wang, Y., Zhang, Q., Xia, Y., Qiu, M., Lin, Y., Li, H., Kong, L., Fang, Y., Ye, W., Wang, Y., Dong, S., Zheng, X., Tyler, B. M., and Wang, Y. 2017. A paralogous decoy protects Phytophthora sojae apoplastic effector PsXEG1 from a host inhibitor. Science 355:710-714.

Martin, K., Kopperud, K., Chakrabarty, R., Banerjee, R., Brooks, R., and Goodin, M. M. 2009. Transient expression in Nicotiana benthamiana fluorescent marker lines provides enhanced definition of protein localization, movement and interactions in planta. Plant J. 59:150-162.

Mukhtar, M.S., Carvunis, A.R., Dreze, M., Epple, P., Steinbrenner, J., Moore, J., Tasan, M., Galli, M., Hao, T., Nishimura, M.T., Pevzner, S.J., Donovan, S.E., Ghamsari, L., Santhanam, B., Romero, V., Poulin, M.M., Gebreab, F., Gutierrez, B.J., Tam, S., Monachello, D., Boxem, M., Harbort, C.J., McDonald, N., Gai, L., Chen, H., He, Y., European Union Effectoromics Consortium, Vandenhaute, J., Roth, F. P., Hill, D. E., Ecker, J. R., Vidal, M., Beynon, J., Braun, P., and Dangl, J. L. 2011. Independently evolved virulence effectors converge onto hubs in a plant immune system network. Science 333:596-601.

Nemri, A., Saunders, D. G. O., Anderson, C., Upadhyaya, N. M., Win, J., Lawrence, G. J., Jones, D. A., Kamoun, S., Ellis, J. G., and Dodds, P. N. 2014. The genome sequence and effector complement of the flax rust pathogen Melampsora lini. Front. Plant Sci. 5:98.

Noon, J. B., and Baum, T. J. 2016. Horizontal gene transfer of acetyltransferases, invertases and chorismate mutases from different bacteria to diverse recipients. BMC Evol. Biol. 16:74.

Oh, H.-S., and Collmer, A. 2005. Basal resistance against bacteria in Nicotiana benthamiana leaves is accompanied by reduced vascular staining and suppressed by multiple Pseudomonas syringae type III secretion system effector proteins. Plant J. 44:348-359.

Pelham, H. R., Hardwick, K. G., and Lewis, M. J. 1988. Sorting of soluble ER proteins in yeast. EMBO J. 7:1757-1762.

Petre, B., Joly, D. L., and Duplessis, S. 2014. Effector proteins of rust fungi. Front. Plant Sci. 5:416.

Petre, B., Saunders, D. G., Sklenar, J., Lorrain, C., Win, J., Duplessis, S., and Kamoun, S. 2015. Candidate effector proteins of the rust pathogen Melampsora larici-populina target diverse plant cell compartments. Mol. PlantMicrobe Interact 28:689-700.

Petre, B., Lorrain, C., Saunders, D. G., Win, J., Sklenar, J., Duplessis, S., and Kamoun, S. 2016a. Rust fungal effectors mimic host transit peptides to translocate into chloroplasts. Cell. Microbiol. 18:453-465.
Petre, B., Saunders, D. G., Sklenar, J., Lorrain, C., Krasileva, K. V., Win, J. Duplessis, S., and Kamoun, S. 2016b. Heterologous expression screens in Nicotiana benthamiana identify a candidate effector of the wheat yellow rust pathogen that associates with processing bodies. PLoS One 11:e0149035.

Priault, M., Camougrand, N., Kinnally, K. W., Vallette, F. M., and Manon, S. 2003. Yeast as a tool to study Bax/mitochondrial interactions in cell death. FEMS Yeast Res. 4:15-27.

Qi, M., Link, T. I., Muller, M., Hirschburger, D., Pudake, R. N., Pedley, K. F. Braun, E., Voegele, R. T., Baum, T. J., and Whitham, S. A. 2016. A small cysteine-rich protein from the Asian soybean rust fungus, Phakopsora pachyrhizi, suppresses plant immunity. PLoS Pathog. 12:e1005827.

Ramachandran, S. R., Yin, C., Kud, J., Tanaka, K., Mahoney, A. K., Xiao, F., and Hulbert, S. H. 2017. Effectors from wheat rust fungi suppress multiple plant defense responses. Phytopathology 107:75-83.

Saunders, D. G. O., Win, J., Cano, L. M., Szabo, L. J., Kamoun, S., and Raffaele, S. 2012. Using hierarchical clustering of secreted protein families to classify and rank candidate effectors of rust fungi. PLoS One 7:e29847.

Schmidt, S. M., and Panstruga, R. 2011. Pathogenomics of fungal plant parasites: What have we learnt about pathogenesis? Curr. Opin. Plant Biol. 14:392-399.

Schwessinger, B., and Zipfel, C. 2008. News from the frontline: Recent insights into PAMP-triggered immunity in plants. Curr. Opin. Plant Biol. 11:389-395.

Sohn, K. H., Lei, R., Nemri, A., and Jones, J. D. G. 2007. The downy mildew effector proteins ATR1 and ATR13 promote disease susceptibility in Arabidopsis thaliana. Plant Cell 19:4077-4090.

Sperschneider, J., Gardiner, D. M., Dodds, P. N., Tini, F., Covarelli, L., Singh, K. B., Manners, J. M., and Taylor, J. M. 2016. EffectorP: Predicting fungal effector proteins from secretomes using machine learning. New Phytol. 210:743-761.

Sperschneider, J., Catanzariti, A. M., DeBoer, K., Petre, B., Gardiner, D. M., Singh, K. B., Dodds, P. N., and Taylor, J. M. 2017. LOCALIZER Subcellular localization prediction of both plant and effector proteins in the plant cell. Sci. Rep. 7:44598.

Thomas, W. J., Thireault, C. A., Kimbrel, J. A., and Chang, J. H. 2009. Recombineering and stable integration of the Pseudomonas syringae pv. syringae $61 \mathrm{hrp} / \mathrm{hrc}$ cluster into the genome of the soil bacterium Pseudomonas fluorescens Pf0-1. Plant J. 60:919-928.

Thomma, B. P. H. J., Nürnberger, T., and Joosten, M. H. A. J. 2011. Of PAMPs and effectors: The blurred PTI-ETI dichotomy. Plant Cell 23: 4-15.

Upadhyaya, N. M., Mago, R., Staskawicz, B. J., Ayliffe, M. A., Ellis, J. G., and Dodds, P. N. 2014. A bacterial type III secretion assay for delivery of fungal effector proteins into wheat. Mol. Plant-Microbe Interact 27: 255-264.

Wang, Y., and Huang, Q. 2011. Assays for effector-mediated suppression of programmed cell death in yeast. Methods Mol. Biol. 712:173-180.

Wei, C.-F., Kvitko, B. H., Shimizu, R., Crabill, E., Alfano, J. R., Lin, N.-C., Martin, G. B., Huang, H.-C., and Collmer, A. 2007. A Pseudomonas syringae pv. tomato DC3000 mutant lacking the type III effector HopQ1-1 is able to cause disease in the model plant Nicotiana benthamiana. Plant J. 51:32-46.

Wei, H. L., Chakravarthy, S., Mathieu, J., Helmann, T. C., Stodghill, P., Swingle, B., Martin, G. B., and Collmer, A. 2015. Pseudomonas syringae pv. tomato DC3000 type III secretion effector polymutants reveal an interplay between HopAD1 and AvrPtoB. Cell Host Microbe 17:752-762.

Whigham, E., Qi, S., Mistry, D., Surana, P., Xu, R., Fuerst, G., Pliego, C., Bindschedler, L. V., Spanu, P. D., Dickerson, J. A., Innes, R. W., Nettleton, D., Bogdanove, A. J., and Wise, R. P. 2015. Broadly conserved fungal effector BEC1019 suppresses host cell death and enhances pathogen virulence in powdery mildew of barley (Hordeum vulgare L.). Mol. Plant-Microbe Interact 28:968-983.

Zha, H. B., Fisk, H. A., Yaffe, M. P., Mahajan, N., Herman, B., and Reed, J. C. 1996. Structure-function comparisons of the proapoptotic protein Bax in yeast and mammalian cells. Mol. Cell. Biol. 16:6494-6508.

Zipfel, C., Robatzek, S., Navarro, L., Oakeley, E. J., Jones, J. D. G., Felix, G., and Boller, T. 2004. Bacterial disease resistance in Arabidopsis through flagellin perception. Nature 428:764-767.

Zipfel, C., Kunze, G., Chinchilla, D., Caniard, A., Jones, J. D. G., Boller, T. and Felix, G. 2006. Perception of the bacterial PAMP EF-Tu by the receptor EFR restricts Agrobacterium-mediated transformation. Cell 125:749-760. 